\title{
Computer Managed Learning and Assessment Integrated Within a Materials Engineering Program for Non-Majors
}

\author{
Aaron S Blicblau \\ Swinburne University of Technology, Hawthorn, Australia
}

\begin{abstract}
This paper reports on an on-line learning initiative in Engineering Materials for first year students in diverse disciplines of engineering. This initiative was developed for general first year engineering students to incorporate an on-line assessment system for the major aspects of learning and teaching: lectures, tutorials and laboratory work. This teaching approach required the availability of a data delivery system (using a proprietary brand of software), for provision of pedagogical material. In particular, tutorial-based inquiry was associated with both a general engineering problem based learning approach and a team approach to problem solving. The hands-on laboratory work was intimately integrated within the data delivery system for both pre laboratory learning, and post laboratory team review in applications utilised by non-materials engineers (notwithstanding other engineering disciplines) and assessment. Feedback from the student and staff about the course content, laboratory structure and data delivery system relevant to many facets of engineering was encouraging and seen to contribute to the overall learning strategy of knowledge of materials within the general engineering environment.
\end{abstract}

\section{Introduction}

All engineers must have a basic knowledge of materials behaviour! The significance of teaching materials to all engineering students was identified by the Institute of Materials in the mid 1980s as being of prime importance ${ }^{1,2}$ as well as by the National Research Council ${ }^{3}$ as being of great importance. The recommendations of these reports give a clue as to why this subject is compulsory. So, all first year engineering students at Swinburne University of Technology (SUT) must enroll and pass a first year subject in Engineering Materials and Processes. However, none of the students will major in Materials, since SUT does not have such a course. It was the foresight of the course designers as early as the 1970s when SUT was still a technical college and before it became a University that materials was a coreenabling subject relevant to all forms and applications of engineering. All engineering students must enroll in first year engineering materials irrespective of their chosen engineering discipline.

There are over 200 enrolments in first year engineering but from at least six different streams of engineering (Table 1), and Engineering Materials is but one of eight subjects taught in first year. This results in two major difficulties. The first, (because it is only one of eight subjects) is that the students are not aware of the importance of materials to their chosen profession, and the second, more pragmatic to the teaching program, is how to deliver teaching matter and assess such a large cohort of (disinterested) students. 
Historically, complete face-to-face lecture delivery and hands-on laboratory work has proved both time consuming and required a large number of staff for delivery and assessment of students' work. The introduction of digital technology into the classroom has greatly simplified the delivery of teaching matter ${ }^{4,5}$. Complete on-line delivery of subject material coupled with online laboratory work has been initiated by a number of workers with varying degrees of success ${ }^{5-8}$ The use of flexible delivery modes of lecture material involves video taped lectures, on-line streaming, and face to face delivery. In addition, the delivery of laboratory material utilises simulation, remote control of experiments, and are conducted on computers using specific software ${ }^{8,9}$. It would seem appropriate that a flexible delivery mode utilize a combination of digital learning material delivery, face-to-face contact and computerbased assessment. This paper discusses one such initiative at SUT for all engineering students enrolled in a variety of engineering disciplines except materials engineering! The range of engineering disciplines, which study Materials in their first year, is shown in Table1.

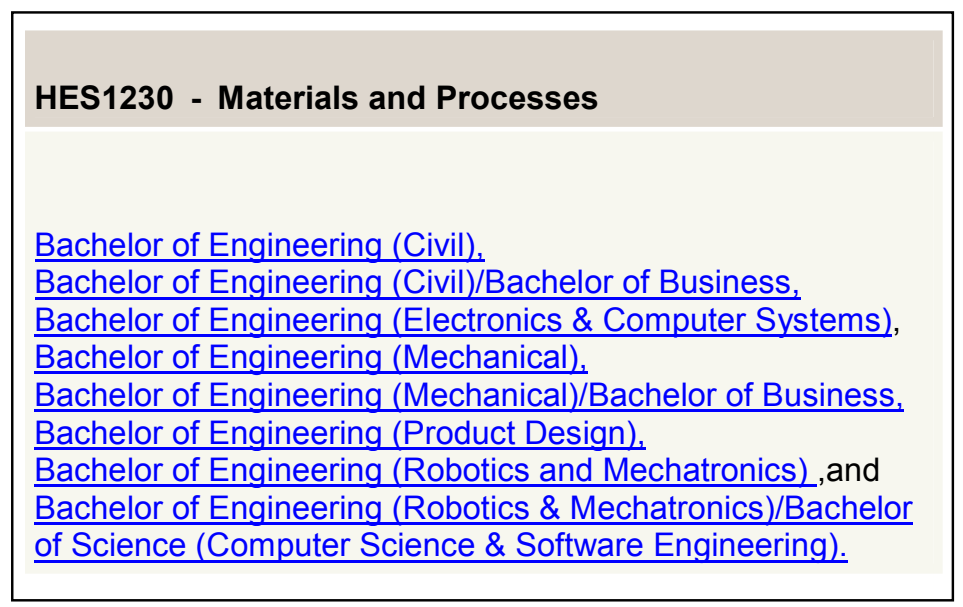

Table 1. Range of Engineering disciplines engaging engineering materials ${ }^{10}$

\section{Engineering Materials Delivery Implementation}

At Swinburne University of Technology relevancy of engineering materials to specific engineering disciplines is inculcated into the syllabus such that each topic delivered to the students has a relevance to some form of engineering. The students are often challenged to illustrate how minor topics in materials are especially relevant to their area of specialization. The lecture delivery is facilitated by video presentations (via digital delivery) and supply of lecture notes prior to the commencement of class (utilising an online data delivery system, Blackboard 6) ${ }^{\oplus 11}$. In addition, tutorial material is supplemented in this way and students are encouraged to communicate with other course members to facilitate collaborative learning. Moreover, laboratory work provided an interesting and useful combination of the flexible delivery of teaching and learning material using on-line materials management system ${ }^{4}$. Specifically, on-line managed laboratory assessment with applications to materials involvement within the student's disciplines is coupled with a hands-on laboratory discovery experience. Students' responses to this approach are discussed and refinements to this learning methodology are proposed.

\section{Traditional Delivery of Lecture Material}

All lecture material was delivered in the traditionally constructed lecture theatre, i.e. large lecture hall with 140 seats arranged theatre style, cramped seats, small writing tableaux and 50 minute or 100 minute lecture sessions. The lecturer performed her activities in front of a 
captive audience- but one who could and would show their appreciation or disdain in various guises, e.g., talking, listening to music on headphones, talking on cell phones or reading a newspaper. The lecturer delivered her material from, overhead transparencies, and "chalk and talk" using a board for writing with students copying and talking for the whole session ${ }^{12}$. Or the lecturer flashed PowerPoint presentations onto a large screen with varying degrees of interest, often sending the students into a mild comatose state ${ }^{13}$. This was a traditional lecture arrangement!

\section{The Modern Lecture Delivery System}

The modern lecture theatre is architecturally similar to the traditional structure, but with one major enhancement; the addition of electronic and computer based resources. However, the presentation of lecture material differed greatly, it utilized digital technology incorporating Powerpoint ${ }^{\odot}$ slides, integrated software and access to the World Wide Web (WWW) ${ }^{14-16}$. Student no longer slavishly copied notes, but had notes made available on the Blackboard ${ }^{\odot}$ system (a data delivery and management system) and (supposedly) downloaded and read by the students. Similarly, a reading guide for that week's lecture topic was provided. To motivate the students' interests, references were made to a variety of sources within the engineering field indicating materials applications. And assessment of material was delivered by incorporation into the on-line learning system. Immediate feedback of assessment encouraged the students to learn and further explore the area under examination. In particular "failures" 17 always generated interest and lively discussions ${ }^{18}$. Especially classic and modern examples in the news were a popular source of debate.

\section{Class Delivery}

To attract the students to the lectures, only $75 \%$ of the notes were provided. The lecture notes were incomplete- only by attending the class and participating in the material delivery could the student complete the learning material. This supplemental material was provided either through interaction with the students, challenging the students to solve minor problems in class, initiating a discussion with neighboring students, or solving a problem related to a specific field of engineering on a "white" board". At first the students were unfamiliar with this style of material delivery, but after a number of classes, began to be involved in the discussion sessions, and often tendered solutions specific to one particular field of engineering. An additional benefit to this material delivery was that the lecturer was able to rest his voice and regroup so enabling him to gather the subject material and proceed in a motivational manner.

\section{Organization of Class Material}

A schematic representation of the overall teaching, tutorial, laboratory and on-line learning and assessment process is shown in Figure 1. Due to the large cohort of students, assessment during the semester was conducted using Blackboard technology. Class tests were developed such that all questions were randomly selected and presented to the students ${ }^{20-22}$. Although each student worked on an individual set of questions, they were encouraged to work in groups to collaborate, to discuss and to assemble answers, so enabling group learning. Even though each assessment contained a different set of questions in a different order. Two of the quiz questions delivered were based on the lecture material specific to one engineering discipline, and came from the class discussion, not the printed notes. And since the assessment system allowed individual student's engineering preferences to be identified, discipline specific question could be integrated into the assessment program. This was done 
through identification of the students' enrolment ID. So a civil engineering student would receive two questions relevant to her discipline, e.g. "concrete is a composite material because it is composed of..." whereas a biomedical student might be asked e.g. "human bone is a composite material because it is composed of..."

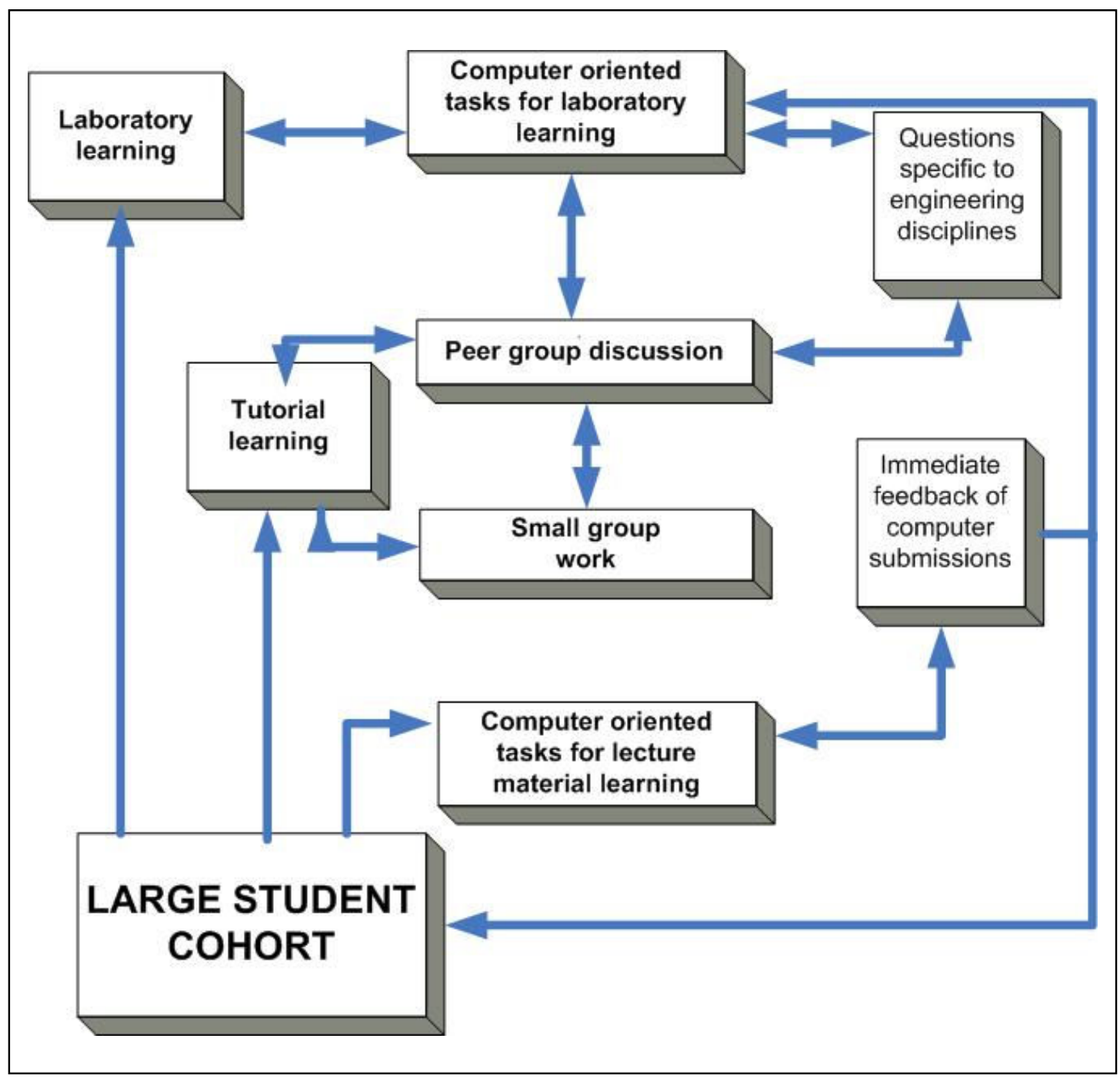

Figure 1. Diagrammatic representation of the on-line teaching and learning program.

\section{Examples of the Topical Approach to Engineering Materials}

Although the diverging nature of engineering is in part due to emergent disciplines such as computer systems engineering, biomedical engineering, product design engineering and robotics and mechatronics [disciplines taught at SUT] the large first year cohort required a common approach to materials teaching.

The topics delivered were of a general nature, in keeping with the non-specific discipline enrolment status of engineering students, and were preceded with real life engineering applications. Examples of such applications are given in Table 2. So, students were 
encouraged to come early to class to understand the relevance of a specific area to an engineering discipline, and during the class the teaching material was enhanced by interactive communication.

\begin{tabular}{|l|l|l|}
\hline General Topic & \multicolumn{1}{|c|}{ Material Specific } & \multicolumn{1}{c|}{ Application } \\
\hline Crystallography & $\begin{array}{l}\text { X-rays, SEM } \\
\text { single crystals }\end{array}$ & $\begin{array}{l}\text { Structure of SiGe chips } \\
\text { Analysis of metal failures }\end{array}$ \\
\hline Strength of materials & $\begin{array}{l}\text { Tensile testing; Impact } \\
\text { testing; fatigue, creep } \\
\text { corrosion }\end{array}$ & $\begin{array}{l}\text { Human body part replacement } \\
\text { Titanic ship } \\
\text { Kansas walkway collapse }\end{array}$ \\
\hline Polymer properties & $\begin{array}{l}\text { Extrusion } \\
\text { Glass transition } \\
\text { temperature }\end{array}$ & $\begin{array}{l}\text { Columbia "o-ring" } \\
\text { Plastic fuel tanks }\end{array}$ \\
\hline Ceramics & PSZ, transformation & $\begin{array}{l}\text { Car exhaust, cutting tools } \\
\text { superconductors }\end{array}$ \\
\hline
\end{tabular}

Table 2. Examples of applications of materials and their properties in a variety of engineering applications.

\section{Laboratory Management and Assessment.}

Traditional approaches to laboratory work, where students must get their hand dirty provide an experiential approach to the understanding of materials behaviour. The assessment of their laboratory work is often laborious and time consuming. And still there is a difficulty in relating the experimental work to the student's chosen area of engineering. An experimental system was developed which incorporated both "hands-on" engineering and on-line assessment and learning of laboratory material ${ }^{8}$. One such area was mechanical testing which is common to all engineering disciplines, and is not difficult to conduct experiments in the laboratory.

Included in Figure 1 is a diagrammatic representation of the laboratory arrangements as they relate to the overall teaching and learning program. The large cohort of students was divided into small groups for laboratory work. Prior to experimental work the students had to complete a 'mini' quiz, which was not assessed, but completion was conditional for participating in the laboratory exercise. All students then actively participated in the experimental work.

\section{Specific Experimental Work}

Each laboratory topic had specific learning objectives associated with it. Examples of laboratory topics and specific learning objectives are given in Table 3 . Here it is seen that the experiments, although of a generic nature, could have applications in many fields of engineering as they were designed to adapt to different student majors. Consequently, during the laboratory session, students were encouraged to discuss various applications of different materials for a variety of components, including a debate of important properties with an associated simple test to determine such a property. 


\begin{tabular}{|l|l|l|}
\hline \multicolumn{1}{|c|}{ Experimental Title } & \multicolumn{1}{|c|}{$\begin{array}{c}\text { Specific Learning } \\
\text { Objectives }\end{array}$} & $\begin{array}{c}\text { Applications to Engineering } \\
\text { Disciplines }\end{array}$ \\
\hline Tensile Testing of Materials & $\begin{array}{l}\text { To demonstrate the } \\
\text { difference in tensile strengths } \\
\text { and elongation of metals and } \\
\text { polymers }\end{array}$ & $\begin{array}{l}\text { Mechanical, Civil, Product } \\
\text { Design, Robotics and } \\
\text { Mechatronics }\end{array}$ \\
\hline Stress concentration & $\begin{array}{l}\text { To demonstrate the effect of } \\
\text { a hole on the stress } \\
\text { concentration in a sheet of } \\
\text { rubber. }\end{array}$ & $\begin{array}{l}\text { Mechanical, Civil, Product } \\
\text { Design, Robotics and } \\
\text { Mechatronics }\end{array}$ \\
\hline Cold work and annealing & $\begin{array}{l}\text { To demonstrate the } \\
\text { phenomena of cold work and } \\
\text { the effect of annealing on } \\
\text { brass. }\end{array}$ & $\begin{array}{l}\text { Mechanical, Civil, Product } \\
\text { Design, Robotics and } \\
\text { Mechatronics }\end{array}$ \\
\hline
\end{tabular}

Table 3. Examples of laboratory topics together with specific learning objectives.

One common property suggested was strength, and a test was tensile testing and its application in a specific discipline. Within the laboratory experiments tensile tests were carried out using different metal samples (these illustrate a number of phenomena; plastic deformation, yielding, Young's modulus, stiffness) and different polymer test pieces (illustrating viscoelastic behavior, high strain and the effect of temperature-glass transition temperature). They discussed in class the applications of the tests to different fields of engineering and how they may apply their knowledge to satisfy selection, quality control aspects or relevant standards for acceptance of components ${ }^{7,23}$.

\section{On-line Learning Management.}

Results from the experimental work were assembled by all the students, but not analysed. For analysis and submission of experimental of results, students were required to undertake an online learning exercise based on their results ${ }^{24}$. The students were asked to work in groups, which was a foreign idea, as it seemed they were cheating! For example, as the group of students sat around the computer they discussed each other's questions. When approached by a staff member, the students were embarrassed that they worked together, but were told that is was appropriate and were encouraged to work and discuss in groups. In reality, they are learning from each other!

\section{Non-Materials Engineering Applications}

Moreover the online exercises were somewhat different for each individual student. Although the basic questions were similar (a random selection of questions is selected by the computer), and required a selection or calculation, each student was also presented with a problem requiring a solution within a non-materials engineering field. 
For example, at the group discussion of experimental results, a number of the computer generated queries were concerned with applications to engineering areas which utilized materials to arrive at the final component property. At this stage it was not important which field of engineering the student was enrolled in, but that the student think outside her or his own sphere. This is an extension of the earlier exercise where the students discussed the appropriateness of mechanical testing to a particular field of engineering.

\section{Learning by On-line Feedback}

Once the computer tasks had been completed, there was immediate feedback of results. If the students were not satisfied with the results they could have another attempt- but they were presented with a different selection of questions. Sometimes the students performed better or worse than their first attempt, but they had learnt more by their second attempt. The highest score was the one they are allowed to keep as an indication of their test score.

\section{Student Knowledge of Tensile Testing Applications}

Examples of student ideas of appropriateness of tensile testing assembled from the on-line quiz are shown in Table 4. These areas were obtained from the quiz results as well as student discussions using the online discussion facility of Blackboard, a popular mode of communication. It was non-threatening and non-prescriptive, so all forms of discussion was able to take place.

In many instances the on-line discussion mode was outside of class contact hours or varsity attendance times. There was a time shift in communication, which allowed for additional e-group learning to be done.

\begin{tabular}{|l|l|}
\hline \multicolumn{1}{|c|}{ Discipline } & \multicolumn{1}{c|}{ Student Application } \\
\hline Electronics and Computer Systems & $\begin{array}{l}\text { Computer casings, printed circuit boards, } \\
\text { computer chips }\end{array}$ \\
\hline Civil & Bridges, roads, tunnels, road barriers \\
\hline Mechanical & Gears, engine mountings, crankshafts \\
\hline Robotics and Mechatronics & Robot arms, grippers, joints \\
\hline Product Design & $\begin{array}{l}\text { Lego }{ }^{\odot} \text { kitchen utensils, automobile } \\
\text { components }\end{array}$ \\
\hline Biotechnology & Body replacement hips, skin for burns \\
\hline
\end{tabular}

Table 4. Examples of student ideas of appropriateness of tensile testing.

\section{Student Response to Computer Laboratory Management}

When the students first encountered the online laboratory assessment and discussion, they were hesitant about its pedagogical usefulness. Often, they had not been exposed to computer managed learning, only to computer-based assessment, and especially within a laboratory environment. In addition, the discipline specific questions encouraged inter group discussion and understanding of alternate engineering applications. According to student feedback, the assessment process had been successful for the grading process and especially for the timely 
response. It also provided an avenue for students to learn outside of the formal classroom environment.

An end-of-course evaluation, undertaken by students in anonymity, highlighted the best and worst parts of the course delivery. Shown in Table 5 is a summary of the comments made by students in response to four major questions outlined in the survey

\begin{tabular}{|l|l|}
\hline \multicolumn{1}{|c|}{ Question (60 per cent response) } & \multicolumn{1}{c|}{ Summary of response } \\
\hline The subject was well organized & 80 per cent positive \\
\hline The assessment requirements were clear & 76 per cent positive \\
\hline What was the best aspect of the subject? & $\begin{array}{l}\text { "...the laboratories because you actually } \\
\text { get to see what happens...," } \\
\text { “...and relates to the lectures...", } \\
\text { “...on-line tests...", } \\
\text { "....ability to work at own speed...." }\end{array}$ \\
\hline $\begin{array}{l}\text { What aspect of this subject needs } \\
\text { improvement? }\end{array}$ & "..need full set of lecture notes...", \\
\hline
\end{tabular}

Table 5. Summary of student response to subject survey

Although the delivery of the laboratory work and assessment rated well, there were some preliminary "hiccoughs", as indicated by a number of responses; refinement of the laboratory delivery work is currently being implemented.

A comparison of test score results with those obtained by students from the previous three years indicated an improvement in the overall grade. However, this could not be measured accurately, as the background of each cohort of students in the various years of intake was not identical. A comprehensive assessment of student grades is currently being proposed as a longitudinal three-year study.

\section{Concluding Remarks}

The implementation of on-line subject delivery and assessment for engineering materials in a first year course delivery mode was seen as a positive step by all engineering students. Even though they were not materials engineering majors, they gained a basic knowledge of applications and mechanical properties of materials when considered within a specific engineering discipline. Participation by the students was enhanced using an on-line approach to subject delivery and assessment. The general feedback response was positive, especially for the understanding of the relevance of mechanical properties of materials to overall engineering.

\section{Acknowledgements}

I wish to acknowledge the many discussions and coffee excursions with Ms. Catherine Pocknee of Swinburne University of Technology, Teaching and Learning Support, for her encouragement to undertake this work. 


\section{Bibliography}

(1) Bonfield, W., Brown, L., Chadwick, G. A., Clarke, M., Hawkins, D. N., Menzies, I. A., Neufeld, P., Plumbridge, W. J. and Stammers, M. P. Metallurgist and Materials Technologist, Materials Teaching a working party report, $1984,16,391$.

(2) Plumbridge, W. J. Metals and Materials, Teaching "Materials" to engineering Students, 1985, 1, 168.

(3) Chaudri, P. and Flemings, M. Materials Science and Engineering for the 1990s; National Research Council, National Academic Press: Washington, 1990.

(4) Blicblau, A. S. and Pocknee, C. "A Multi-Modal Approach to Teaching and Learning: A Case Study of Teaching Materials and Process Engineering"; 14th Annual Conference for Australian Association for Engineering Education, 2003, Melbourne.

(5) Ciglarlic, M. and Vidmar, T. European Journal of Engineering Education, Use of Internet

Technologies for Teaching Purposes, 1998, 23, 497.

(6) Crosthwaite, C. and Simmons, J. "Curriculum Diversity in the First Year"; 14th Annual Australian Association Engineering Education Conference, 2003, Melbourne.

(7) Lemckert, C. "Enhancement of Internet-Mediated Laboratory Experiments"; 13th Annual Conference of the Australian Association of Engineering Education, 2003, Conference.

(8) Gillet, D., Latchman, H. A., Salzmann, C. and Crisalle, O. D. Journal of Engineering Education, Hands-On Laboratory Experiments in Flexible and Distance Learning, 2001, 90, 187.

(9) Alexander, D. G. and Smesler, R. E. Journal of Engineering Education, Delivering an Engineering Laboratory Course Using the Internet, the Post Office, and a Campus Visit. 2003, 91, 79.

(10) CourseFinder. Swinburne University of Technology, http://domino.swin.edu.au/cd31.nsf/searchweb?OpenForm\&Seq=1 (accessed 26th November 2003).

(11) Blackboard, I. http://www.blackboard.com/ (accessed 26th November 2003).

(12) McKeachie, W. J. Teaching Tips: Strategies, research, and theory for college and university teachers; Houghton Mifflin, Boston, 2002.

(13) Brown, D. G. Syllabus, Powerpoint Induced Sleep. 2001, 17.

(14) Hylnka, D. and Mason, R. Educational Technology, Powerpoint in the Classroom: What is the Point? $1998,45$.

(15) Ewald, H. and Page, G. F. Global Journal of Engineering Education, Performing experiments by remote control using the Internet, 2000, 4, 287.

(16) Mason, R. Syllabus, Powerpoint in the classroom: Where is the Power? 1998, 42.

(17) Hendley, V. Prism, The Importance of failure, 1998, 8, 19.

(18) Felder, R. M. Journal of College Science Teaching, Reaching the Second Tier-Learning and Teaching in College Science Education, 1993, 23, 286.

(19) Felder, R. M. "Beating the numbers game: Effective teaching in large classes"; ASEE Conference proceedings, 1997, Milwaulkie, WI.

(20) Carbone, A. P., Schendzierlorz, A. P. and Zakis, J. D. International Journal of Electrical Engineering Education, Electronic Assessment and Self-Paced Learning on the Web Using a Multiple-Choice Quiz Generator, 2000, 37, 119.

(21) Christe, B. "Writing On-line Exam Questions that discourage Dishonesty"; proceedings of the American Society for Engineering Education, 2003, Nashville.

(22) Marks, B., P. Journal of Engineering Education, Web-based Readiness Assessment Quizzes, 2002, 91 , 97.

(23) Ogot, M., Elliot, G. and Glumc, N. Journal of Engineering Education, An Assessment of In-Person and Remotely Operated Laboratories, 2003, 92, 57.

(24) Lemckert, C. and Florance, J. R. British Journal of Educational Technology, Real-Time Internet Mediated Laboratory Experiments for Distance Education Students, 2002, 33, 99.

\section{Biography}

Aaron Blicblau is a senior lecturer of materials engineering at Swinburne University of technology. He teaches engineering materials to freshman engineering students from a variety of engineering disciplines. For sophomore and later year students he teaches materials engineering failure analysis, manufacturing processes and selection of materials. His teaching in senior year is focused on the capstone mechanical engineering course. 